\title{
Networked T Cell Death following Macrophage Infection by Mycobacterium tuberculosis
}

\author{
Stephen H.-F. Macdonald*, Elliott Woodward, Michelle M. Coleman, Emma R. Dorris, \\ Parthiban Nadarajan, Wui-Mei Chew, Anne-Marie McLaughlin, Joseph Keane
}

Department of Clinical Medicine, Trinity Institute of Molecular Medicine, St. James's Hospital, Dublin, Ireland

\begin{abstract}
Background: Depletion of T cells following infection by Mycobacterium tuberculosis (Mtb) impairs disease resolution, and interferes with clinical test performance that relies on cell-mediated immunity. A number of mechanisms contribute to this $T$ cell suppression, such as activation-induced death and trafficking of $T$ cells out of the peripheral circulation and into the diseased lungs. The extent to which Mtb infection of human macrophages affects $T$ cell viability however, is not well characterised.

Methodology/Principal Findings: We found that lymphopenia $\left(<1.5 \times 10^{9}\right.$ cells/l) was prevalent among culture-positive tuberculosis patients, and lymphocyte counts significantly improved post-therapy. We previously reported that Mtbinfected human macrophages resulted in death of infected and uninfected bystander macrophages. In the current study, we sought to examine the influence of infected human alveolar macrophages on $\mathrm{T}$ cells. We infected primary human alveolar macrophages (the primary host cell for Mtb) or PMA-differentiated THP-1 cells with Mtb H37Ra, then prepared cellfree supernatants. The supernatants of Mtb-infected macrophages caused dose-dependent, caspase-dependent, $T$ cell apoptosis. This toxic effect of infected macrophage secreted factors did not require TNF- $\alpha$ or Fas. The supernatant cytotoxic signal(s) were heat-labile and greater than $50 \mathrm{kDa}$ in molecular size. Although ESAT- 6 was toxic to T cells, other Mtbsecreted factors tested did not influence T cell viability; nor did macrophage-free Mtb bacilli or broth from Mtb cultures. Furthermore, supernatants from Mycobacterium bovis Bacille de Calmette et Guerin (BCG)- infected macrophages also elicited T cell death suggesting that ESAT-6 itself, although cytotoxic, was not the principal mediator of T cell death in our system.
\end{abstract}

Conclusions: Mtb-Infected macrophages secrete heat-labile factors that are toxic to $\mathrm{T}$ cells, and may contribute to the immunosuppression seen in tuberculosis as well as interfere with microbial eradication in the granuloma.

Citation: Macdonald SH-F, Woodward E, Coleman MM, Dorris ER, Nadarajan P, et al. (2012) Networked T Cell Death following Macrophage Infection by Mycobacterium tuberculosis. PLoS ONE 7(6): e38488. doi:10.1371/journal.pone.0038488

Editor: Pere-Joan Cardona, Fundació Institut d'Investigació en Ciències de la Salut Germans Trias i Pujol. Universitat Autònoma de Barcelona. Ciberes, Spain

Received September 7, 2011; Accepted May 6, 2012; Published June 4, 2012

Copyright: (C) 2012 Macdonald et al. This is an open-access article distributed under the terms of the Creative Commons Attribution License, which permits unrestricted use, distribution, and reproduction in any medium, provided the original author and source are credited.

Funding: This work was funded by the Science Foundation Ireland (SFI; www.sfi.ie) and the Health Research Board (HRB; www.hrb.ie). JK, SHFM and MMC were supported by SFI as part of the Immunology Research Centre, (SFI) Strategic Research Cluster grant (07/SRC/B1144 Cluster Grant E02209420). ERD was funded by the HRB's PhD Scholars' Program. The funders had no role in study design, data collection and analysis, decision to publish, or preparation of the manuscript.

Competing Interests: The authors have declared that no competing interests exist.

*E-mail: macdonaldez@gmail.com

\section{Introduction}

Tuberculosis (TB) in an immunosuppressive illness and lymphopenia often occurs in TB patients [1,2]. Rather than being an epiphenomenon, it is more likely that this $\mathrm{T}$ cell deficiency contributes to pathogen persistence in the host, and the lack of a meaningful immune response during chronic $\mathrm{TB}$ infection. Indeed, intracellular pathogens such as Mycobacterium tuberculosis (Mtb) must suppress immunity to survive within an infected host $[3,4]$, and the status of host T lymphocytes is a critical factor in determining the resolution of chronic infections, like tuberculosis. The mechanism of lymphopenia in tuberculosis patients is poorly understood, but may involve activation-induced apoptosis or sequestration of lymphocytes to inflamed organs such as the lung.

$\mathrm{T}$ cells enhance the activity of phagocytes against Mtb and other intracellular microbes by delivering activating signals, including interferon- $\gamma(\mathrm{IFN}-\gamma)[5]$, subsequently upregulating key processes such as nitric oxide generation and apoptosis [6,7]. Accordingly, the significant $\mathrm{T}$ cell depletion which accompanies active TB disease is associated with poor prognosis $[1,8]$ as well as diminished cytokine responses which may persist even following successful antitubercular therapy [9]. T cell apoptosis is also an abundant feature of the granuloma, which is a highly organised structure comprising a necrotic centre containing bacteria, dead and infected macrophages, as well as multinucleate giant cells, surrounded by a peripheral cuff of lymphocytes [10,11]. Host phagocyte death can be inhibited by Mtb [12], and it has been shown, by Mustafa et al., that infected cells at the granuloma centre express reduced levels of apoptotic markers such as caspase 3 than those that are uninfected [13]. However significant levels of proapoptotic surface molecules such as Fas ligand are expressed at the periphery of the granuloma, where $\mathrm{T}$ cells accumulate [14]. This may represent an infection-induced 'keep out' signal that prevents $\mathrm{T}$ cell penetration into the granuloma centre. Additionally, Hirsch et al. have described an increased susceptibility to 
apoptosis in $\mathrm{T}$ cells taken from tuberculosis patients [15], and research by Sharma et al. indicated that infected macrophages can signal $\mathrm{T}$ cell apoptosis [16]. The mechanism of this $\mathrm{T}$ cell death response is unclear, and it is not known if Mtb-infected human alveolar macrophages (AMs) can supply this immunosuppressive death signal.

We found that lymphopenia was prevalent in our culture positive tuberculosis patients, and there was a statistically significant recovery of lymphocyte counts after anti-TB treatment. Because animal model work had associated low lymphocyte counts with death following mycobacterial infection [17], we sought to investigate the toxic effect of infected macrophages on T cells. We have previously reported that human alveolar macrophage infection by Mtb can elicit signals that kill infected cells and nearby uninfected bystander macrophages, in what is likely a hostprotective response. The macrophage death response deprives the bacilli of their replicative niche cell and facilitates delivery of mycobacterial antigens to APGs, enabling antigen presentation $[18,19]$. Even as the infected human alveolar macrophage death response may support TB immunity, it is likely that a death signal delivered to nearby $\mathrm{T}$ cells would diminish the host response $[12,20]$. We now report that Mtb-infected human alveolar macrophages do cause networked, caspase-dependent lymphocyte apoptosis. Like alveolar macrophages, cell-free culture supernatants from Mtb-infected THP-1 macrophages reliably induced this $\mathrm{T}$ cell killing phenotype. We found that this human macrophage cell line recapitulates this host response to infection, which is dosedependent, but TNF- $\alpha$ and Fas-independent. We show that macrophage-free Mtb bacilli are not sufficient to signal $\mathrm{T}$ cell death, which suggests a role for a PAMP/DAMP complex derived from infected cells. Thus far, we have begun to characterise the $\mathrm{T}$ cell death-inducing signal secreted from infected macrophages, and found it to be heat-labile and greater than $50 \mathrm{kDa}$ in molecular size.

\section{Methods}

\section{Ethics Statement}

For patient lymphocyte counts, all analysis was performed anonymously on preexisting clinical data, therefore consent was not required. For alveolar macrophage isolation, informed written consent was obtained as part of the project "Airway gene expression profiling and immune response to lung disease", approved by the St. James's Hospital/AMNCH Research Ethics Committee. Only the "Immune Response to Lung Disease" aspect of the ethics approval was used in this manuscript.

\section{Reagents and Antibodies}

Except where specified, all reagents and materials were obtained from Sigma-Aldrich. Anti-human TNF- $\alpha$ blocking antibody (cat\# MAB210) and mouse IgG1 isotype control (cat\# MAB002) were obtained from R\&D systems. Anti-human Fas blocking antibody ZB-4 (cat\# 05-338) was obtained from Millipore. Mtb secreted factors $16 \mathrm{kDa}$ (cat\# NR-14860), 45 kDa (cat\# NR-14862), Antigen85 (cat\# NR-14855), ESAT-6 (cat\# NR-14868), GroES (cat\# NR-14861), ManLAM (cat\# NR-14848) and Phos 1 (cat\# NR-14859) were obtained from BEI resources, NIAID, NIH under the TB Vaccine Testing and Research Materials (TBVTRM) contract no. HHSN266200400091C awarded to Colorado State University.

\section{Patient Lymphocyte Counts}

All analysis of patient data was carried out anonymously. We performed a retrospective analysis of lymphocyte counts of

\section{LYMPHOCYTE COUNTS PRE- AND POST- TREATMENT}

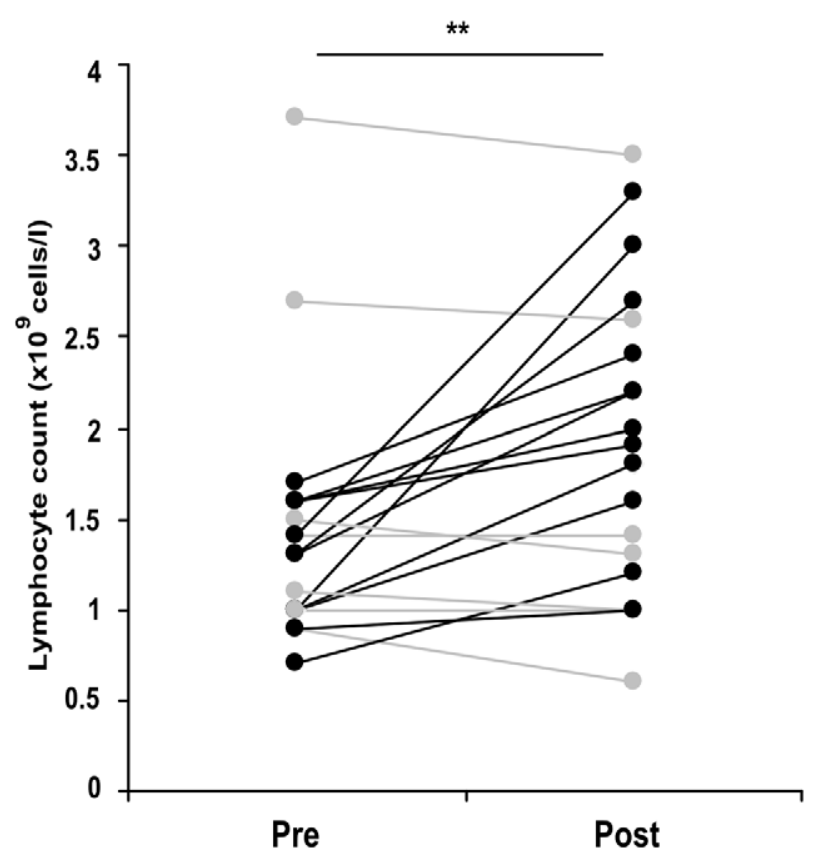

Figure 1. Patient lymphocyte counts pre- and post antitubercular chemotherapy. Lymphocyte counts were taken, before and after treatment, from twenty patients who were culture-positive for Mtb. Each joined pair of data points represents pre- and post-therapy lymphocyte counts $\left(\times 10^{9}\right.$ cells/l) from a single patient. Data from patients whose lymphocyte counts recovered following treatment are shown in black; counts from patients whose lymphocyte counts fell or did not change are shown in grey. ${ }^{* *}=p<0.01$, paired Student's t test comparing pre-treatment vs post-treatment counts.

doi:10.1371/journal.pone.0038488.g001

twenty Mtb-culture positive patients recruited consecutively from our TB service at St James' Hospital, starting November 2009. Pre-treatment lymphocyte counts were performed on the date of diagnosis prior to initiating anti-tuberculous treatment and post treatment lymphocyte counts were performed after at least 2 months of treatment. Lymphopenia was defined as a lymphocyte count of less than $1.5 \times 10^{9} / 1$. Immunosupressed patients (e.g. HIV-positive, steroid use) and cancer patients were excluded.

\section{Culture of Mycobacterium Tuberculosis}

M.tuberculosis H37Ra and M.bovis BCG, obtained from ATCC, were grown to $\log$ phase at $37^{\circ} \mathrm{C}$ in $5 \% \mathrm{CO}_{2}$ in Middlebrook $7 \mathrm{H} 9$ broth (Difco), supplemented with albumin-dextrose-catalase (Becton Dickinson) and 0.05\% Tween-80 (Difco), and made up in endotoxin-free water.

\section{Isolation of Primary Human Alveolar Macrophages}

Human alveolar macrophages were obtained at bronchoscopy, after written consent, under a protocol approved by the St. James's Hospital/AMNCH ethics board. Cells in bronchoalveolar lavage fluid were passed through a $100 \mu \mathrm{m}$ nylon cell strainer (BD Bioscience), then centrifuged for $15 \times \mathrm{min}$ at $200 \times \mathrm{g}$ and subsequently resuspended in RPMI supplemented with $10 \%$ human serum, $0.2 \%$ Fungizone, and $0.1 \%$ Cefotaxime. AMs were then seeded onto tissue culture plates at a density of $5 \times 10^{5}$ cells per $\mathrm{ml}$, and incubated overnight at $37^{\circ} \mathrm{C}$ in $5 \%$ $\mathrm{CO}_{2}$ before use. 
A

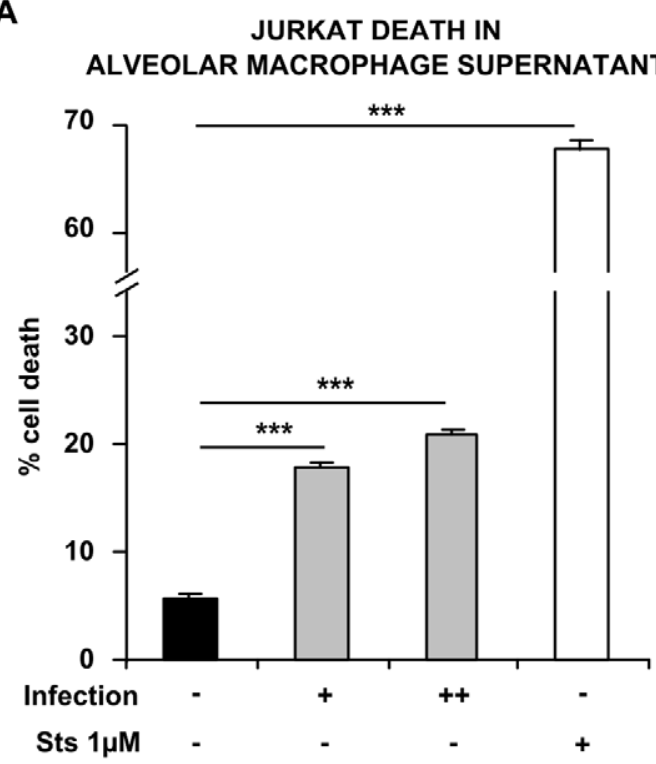

PBTL DEATH IN

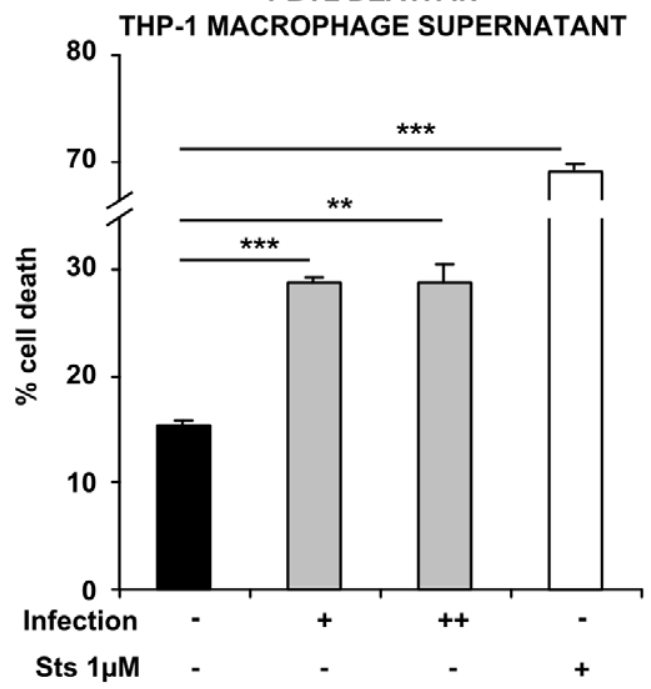

JURKAT DEATH IN

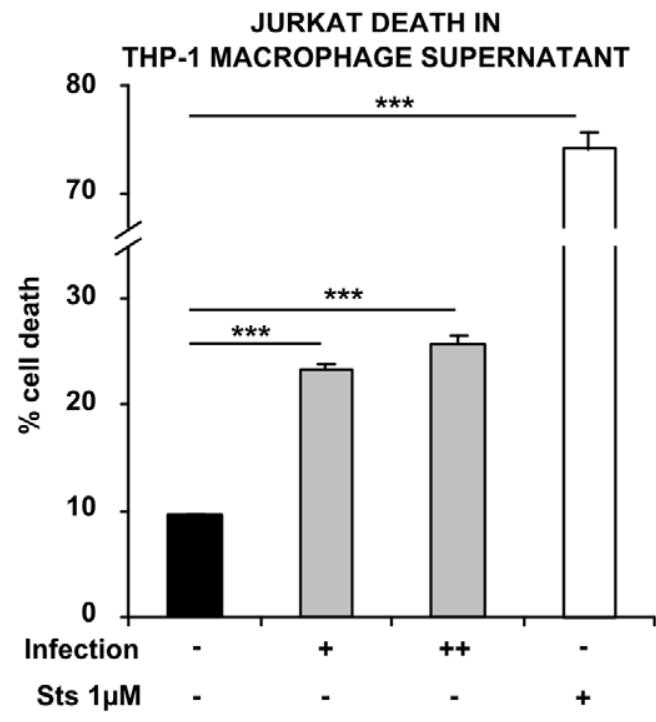

B

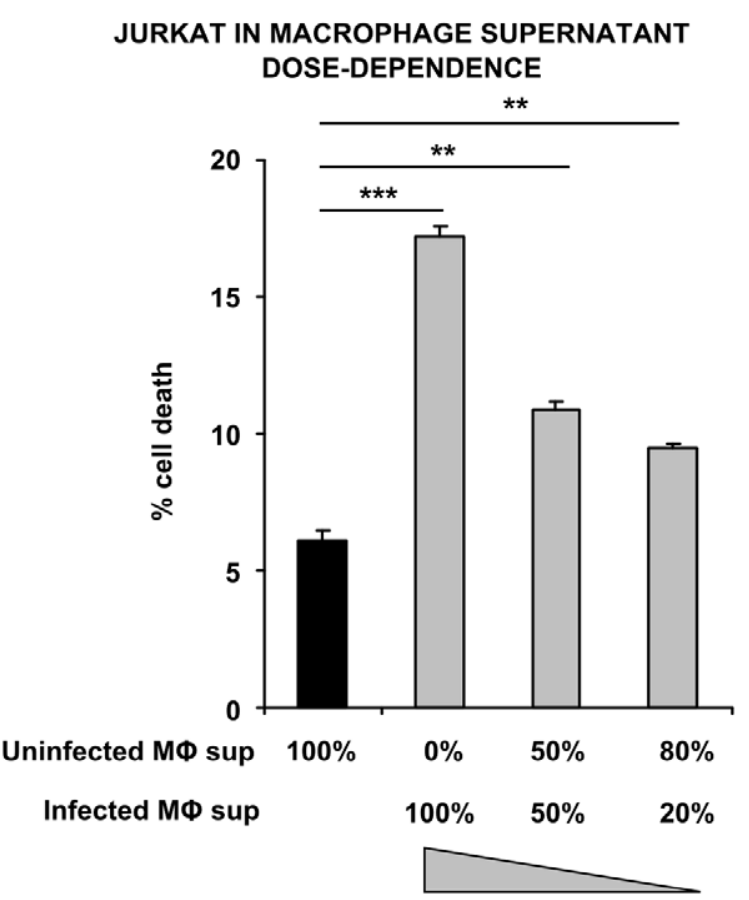

C
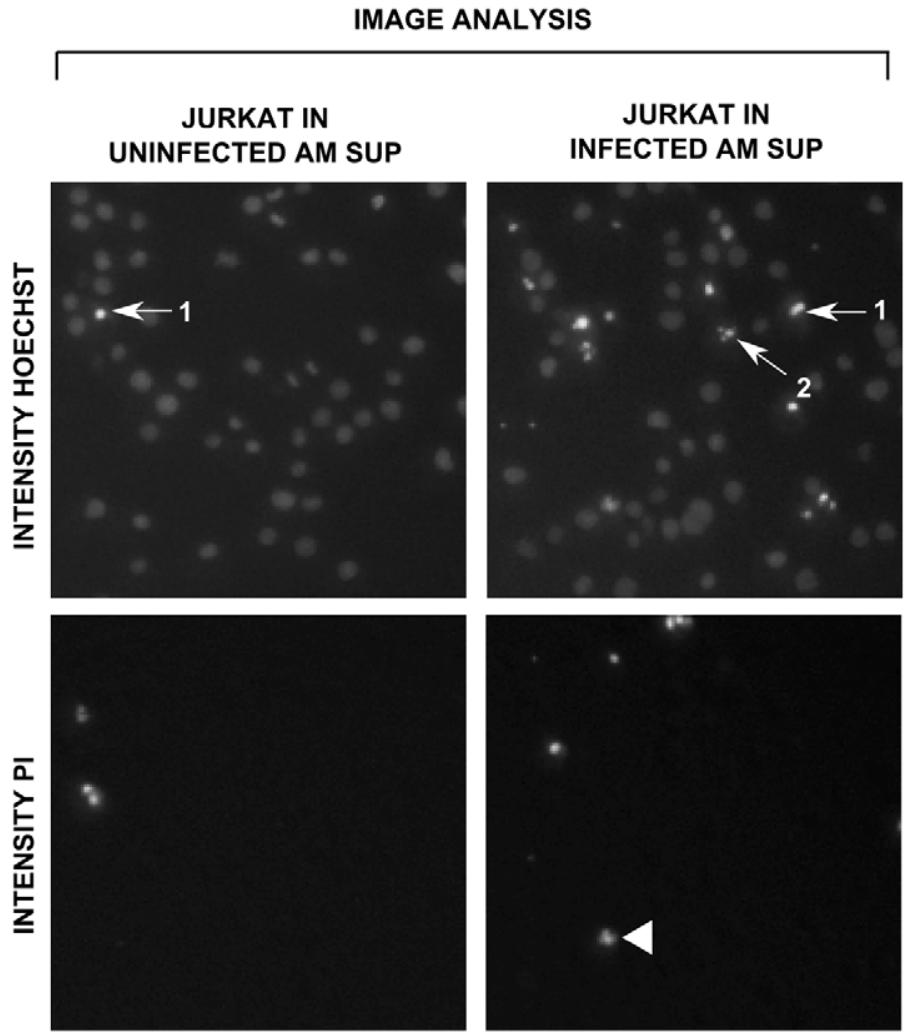
Figure 2. M.tuberculosis-infected macrophage supernatants are toxic to T cells. (A) Jurkat T cells underwent significantly increased cell death in cell-free supernatants of low MOI and high MOI Mtb-infected human primary alveolar macrophages (AMs) (shaded bars; infection + and ++, respectively), compared to those of uninfected AMs (closed bars, infection -). Staurosporine $1 \mu \mathrm{M}$ was used as a positive control to induce cell death (open bars). Similar effects were observed on PBTL and Jurkat T cells exposed to the cell-free supernatants of uninfected/infected THP-1 macrophages. (B) Jurkat cell death in infected THP-1 macrophage supernatant occurred in a dose-dependent manner; infected macrophage supernatants were diluted to $50 \%$ and $20 \%$ in uninfected supernatant, reducing the level of T cell killing. (C) Example cropped fluorescence intensity images for Hoechst and PI staining from Jurkats incubated in uninfected and infected AM supernatants. Images were processed using automated INCell image analysis to detect apoptotic condensed and fragmented nuclei (arrow 1 and 2, respectively) and PI-positive cells (arrow head). Data in each panel are from one representative experiment, showing mean percentage cell death \pm SEM from incubations performed in triplicate. ${ }^{* *}=$ $p<0.01,{ }^{* * *}=p<0.001$, Student's $t$ test relative to uninfected control.

doi:10.1371/journal.pone.0038488.g002

\section{Culture of Human Cells}

Cells of the human T cell leukaemia line, Jurkat (ATCG \#TIB152), and the monocytic leukaemia line, THP-1 (ATCG \#TIB202) were routinely cultured at $37^{\circ} \mathrm{C}$ in $5 \% \mathrm{CO}_{2}$ in RPMI 1640 , supplemented with $10 \%$ FBS (hereafter referred to as 'complete RPMI'), at a density of between $1 \times 10^{5}-1 \times 10^{6}$ and $2 \times 10^{5}-8 \times 10^{5}$ cells $/ \mathrm{ml}$ respectively.

\section{Isolation of Primary Human Peripheral Blood T lymphocytes (PBTL)}

Lymphocytes were isolated from human whole blood provided by the Irish Blood Transfusion Service. Briefly, blood was diluted 1:2 with sterile PBS, then layered onto lymphoprep and spun at $1200 \times \mathrm{g}$ without brake for $20 \mathrm{~min}$ at room temperature. Buffy coats were removed, and then washed three times with PBS. Cells were then resuspended in serum-free RPMI, and incubated for $2 \mathrm{~h}$ at $37^{\circ} \mathrm{C}$ in $5 \% \mathrm{CO}_{2}$ to remove monocytes. Nonadherent cells were then harvested and resuspended in complete RPMI $+2 \mu \mathrm{g} / \mathrm{ml}$ PHA and incubated for 3 days at $37^{\circ} \mathrm{C}$ in $5 \% \mathrm{CO}_{2}$. Subsequently, cells were washed in complete RPMI and resuspended at a density of $1.5 \times 10^{6} \mathrm{cells} / \mathrm{ml}$ in complete RPMI supplemented with $20 \mathrm{ng} /$ $\mathrm{ml} \mathrm{IL-2} \mathrm{(Peprotech),} \mathrm{then} \mathrm{incubated} \mathrm{for} 5$ days at $37^{\circ} \mathrm{C}$ in $5 \% \mathrm{CO}_{2}$ to generate PBTLs.

\section{M. tuberculosis Infection of Macrophages}

M.tuberculosis H37Ra or M.bovis BCG bacilli growing in the $\log$ phase were centrifuged at $3000 \times \mathrm{g}$ for $10 \mathrm{~min}$, and then resuspended in complete RPMI. This suspension was then passed 8 times through a $25 \mathrm{G}$ needle, before centrifugation at $100 \times \mathrm{g}$ for 3 min to remove remaining clumped bacteria. Bacterial suspension was then transferred to a fresh tube, and subsequently used for infection of AMs prepared as described above, or THP-1 cells, previously differentiated to a macrophage phenotype by $72 \mathrm{~h}$ incubation with $100 \mathrm{nM}$ Phorbol 12-myristate 13-acetate (PMA). Cells were infected with a range of volumes of Mtb H37Ra or BCG suspension, then following $3 \mathrm{~h}$ incubation, remaining extracellular bacilli were washed off with PBS, and cells were fixed with $2 \%$ paraformaldehyde in PBS for $5 \mathrm{~min}$, and subsequently stained using a Rapid Modified Auramine O Stain Set (Scientific Device Laboratory Inc.) according to the manufacturer's protocol, followed by $5 \mathrm{~min}$ staining with $10 \mu \mathrm{g} / \mathrm{ml}$ Hoechst 33258. Cells were imaged using fluorescent microscopy in order to determine the Multiplicity of Infection (MOI), where a low MOI was defined as $>70 \%$ of cells infected with $1-5$ bacteria, and a high MOI as $>80 \%$ of cells infected with $6-10$ bacteria. Subsequently, AMs at a density of $5 \times 10^{5}$ cells $/ \mathrm{ml}$ or THP-1 macrophages growing at a density of $5 \times 10^{4}$ cells $/ \mathrm{ml}$ in tissue culture plates, were infected in this manner, incubated for $3 \mathrm{~h}$, then remaining extracellular bacilli were washed off and infected cells were incubated for a further $48 \mathrm{~h}$ in complete RPMI. For uninfected controls, cells were processed in parallel, but without addition of bacilli. Following this incubation, supernatants were removed from the cells, then centrifuged at $6,800 \times \mathrm{g}$ to remove any free bacteria, and stored at $-20^{\circ} \mathrm{C}$.

\section{T Cell Culture in Cell-free Supernatants from Mtb- infected Macrophages}

Jurkat $\mathrm{T}$ cells or PBTLs were incubated in 96-well plates at a density of $1 \times 10^{4}$ cells/well, in triplicate, in a volume of $150 \mu \mathrm{l} /$ well, in cell-free supernatants from Mtb- or BCG- infected macrophages. $1 \mu \mathrm{M}$ Staurosporine was used as a positive control for cell death. Following $24 \mathrm{~h}$ incubation, cells were stained simultaneously with $5 \mu \mathrm{g} / \mathrm{ml}$ Propidium Iodide (PI), $20 \mu \mathrm{g} / \mathrm{ml}$ Hoechst 33342 and $50 \mu \mathrm{g} / \mathrm{ml}$ Hoechst 33258, briefly resuspended by gentle pipetting, then plates were centrifuged at $400 \times \mathrm{g}$ for 2 min to bring cells in suspension to the bottom surface of the well. Plates were then imaged using an INCell Analyzer 1000 cellular imaging system (GE Healthcare) and images were analyzed using GE INCell Analyzer 1000 Workstation software version 3.6 (GE Healthcare) as we have previously published [21]. Total cell numbers were detected via Hoechst staining of nuclei, and the dying/dead cells were identified via positivity for PI staining and/ or nuclear condensation, which was characterised by elevated intensity of Hoechst staining within the nuclei (see figure S1). 1218 fields of view per well were acquired.

\section{M. tuberculosis/T Cell Coculture, Supernatant and Secreted Antigen Experiments}

For coincubation experiments, Mtb H37Ra bacilli growing in the log phase were incubated in 96-well plates with $\mathrm{T}$ cells at varying ratios, with a constant $1 \times 10^{4}$ cells per well in triplicate, then imaged with Hoechst/PI staining as before. T cells were also incubated in triplicate in 96-well plates at $1 \times 10^{4}$ cells per well for $24 \mathrm{~h}$ in increasing dilutions of cleared culture supernatant taken from Mtb growing in the log phase in free culture, and then imaged. For secreted antigen experiments, $\mathrm{T}$ cells were incubated in the same manner, in logarithmic dilutions of each antigen in a concentration range of $10 \mu \mathrm{g} / \mathrm{ml}$ to $0.1 \mu \mathrm{g} / \mathrm{ml}$, for $24 \mathrm{~h}$ before imaging.

\section{Manipulation of Infected Macrophage Supernatants}

For blocking antibody experiments, anti-human TNF- $\alpha$ (hereafter referred to as anti-hTNF- $\alpha)(5 \mu \mathrm{g} / \mathrm{ml})$, anti-human Fas (hereafter referred to as anti-Fas) $(2.5 \mu \mathrm{g} / \mathrm{ml})$ or isotype control $\mathrm{IgG}$ at the same concentration were added to supernatants, and incubations carried out as described above. In positive control experiments for TNF-mediated cell killing, cells were incubated for $15 \mathrm{~min}$ in the presence of $0.2 \mu \mathrm{g} / \mathrm{ml}$ cycloheximide, then recombinant human TNF- $\alpha$ (R\&D Systems) was added to $5 \mathrm{ng} /$ $\mathrm{ml}$. In positive control experiments for Fas ligand-mediated cell killing, cells were incubated in the presence of $10 \mathrm{ng} / \mathrm{ml}$ recombinant human Fas ligand (R\&D systems), crosslinked with $10 \mu \mathrm{g} / \mathrm{ml}$ anti- $6 \times$ Histidine (R\&D systems). 
A

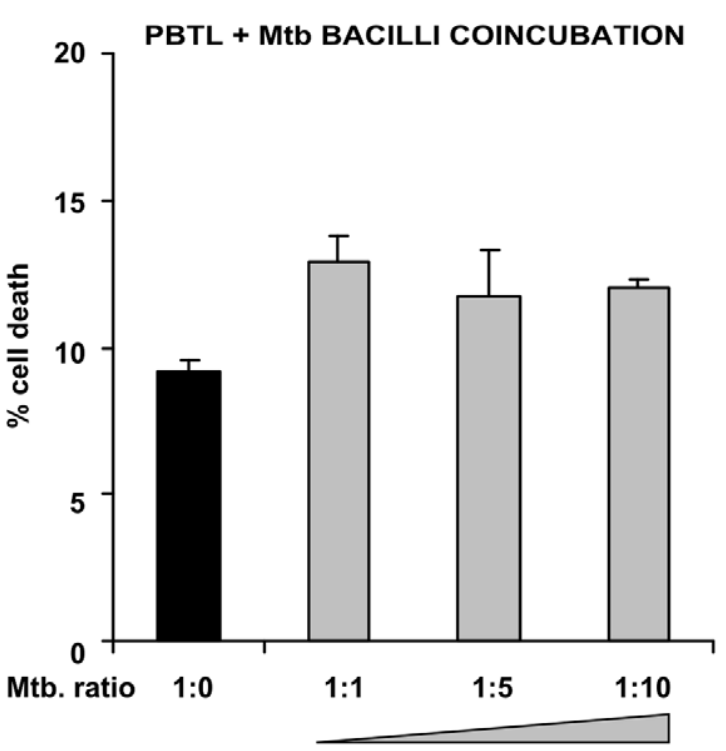

B

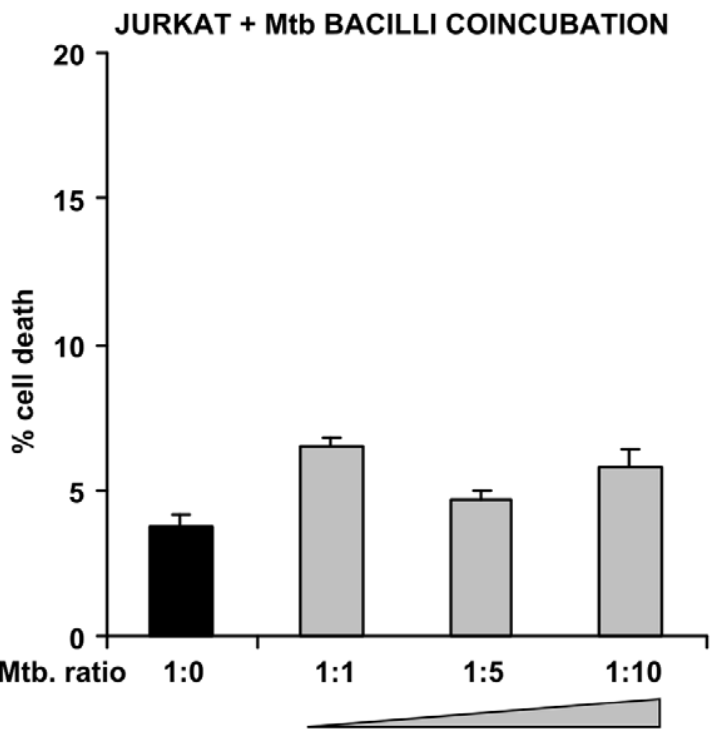

C

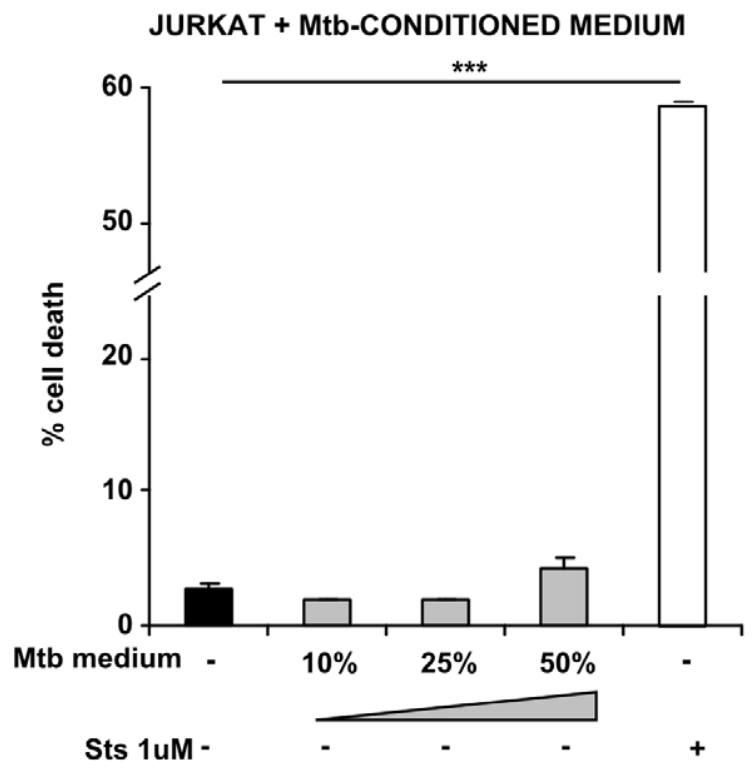

Figure 3. Macrophage-free M.tuberculosis bacilli are not sufficient to induce T cell death. PBTLs (A) and Jurkat T cells (B) were incubated either in complete RPMI only (closed bars) or coincubated with Mtb bacilli at a range of $T$ cell: Mtb ratios (shaded bars). Subsequently, Jurkat $T$ cells were incubated in complete RPMI supplemented with medium taken from Mtb growing in the log phase at a range of ratios (shaded bars) (C). Staurosporine $1 \mu \mathrm{M}$ was used as a positive control to induce cell death. Data in each panel are from one representative experiment, showing mean percentage cell death \pm SEM from incubations performed in triplicate. ${ }^{* * *}=p<0.001$, Student's $t$ test relative to uninfected control.

doi:10.1371/journal.pone.0038488.g003

For heat treatment experiments, supernatants were heated to $95^{\circ} \mathrm{C}$ for $20 \mathrm{~min}$, and then allowed to cool to room temperature before use. Initial experiments (data not shown) indicated that to preserve normal $\mathrm{T}$ cell viability, medium heated in this manner requires subsequent resupplementation with $10 \% \mathrm{FBS}$, therefore all supernatants were resupplemented following heat treatment.

For molecular weight cutoff experiments, supernatants were spun on Amicon Ultra-15 centrifugal filter units with Ultracel-50 membrane (Millipore), then filtrate (hereafter referred to as $<50 \mathrm{kDa}$ fraction) and retentate (hereafter referred to as $>50 \mathrm{kDa}$ fraction) recovered. During optimisation experiments (data not shown), the $>50 \mathrm{kDa}$ fractions were found to affect the basal levels of cell death when applied to $\mathrm{T}$ cells, due to concentration of soluble factors from the medium itself, therefore fractions were diluted to $25 \%$ or $10 \%$ in fresh medium for subsequent experiments.

\section{Statistical Analysis}

In data from patients who underwent antitubercular chemotherapy, a two-tailed, paired Student's $t$ test was used in Microsoft Excel to determine significance between pre- and post-treatment lymphocyte counts. In all other cases, experiments were carried out in triplicate, and were performed a minimum of three times, except where specifically stated otherwise, with representative data from one experiment shown in each figure. Results were expressed as mean \pm SEM, and statistical analysis was performed using a two-tailed, unpaired Student's $t$ test in Microsoft Excel. A $p$-value of less than 0.05 was considered to be statistically-significant.

\section{Results}

\section{Lymphopenia is Prevalent in Tuberculosis Patients and} Recovers after Treatment

We assessed the lymphocyte counts of twenty consecutively recruited patients who were culture-positive for Mtb infection, sampled before and after antitubercular chemotherapy. Low levels of lymphocytes $\left(<1.5 \times 10^{9} / 1\right.$ in 13 out of 20 cases) were prevalent at presentation, but significantly improved after treatment $(\mathrm{p}<0.01)$ (fig. 1). This suggests that primary lymphopenia is not the reason for tuberculosis reactivation in this group. It does however link infection burden and inadequate lymphocytes [22]. We then investigated the signaling factors released from Mtbinfected human macrophages that contribute to this clinical phenotype, of lymphocyte death.

\section{M. tuberculosis Infection of Primary Human Alveolar Macrophages Signals T Cell Death}

To investigate whether soluble mediators released during Mtb infection could alter the viability of $\mathrm{T}$ cells in a contactindependent manner, we first infected primary human alveolar macrophages for $48 \mathrm{~h}$ with Mtb H37Ra bacilli, then harvested culture supernatants and applied them to Jurkat T cells for $24 \mathrm{~h}$ before assessing cell death. In Jurkats incubated in cell-free 
A

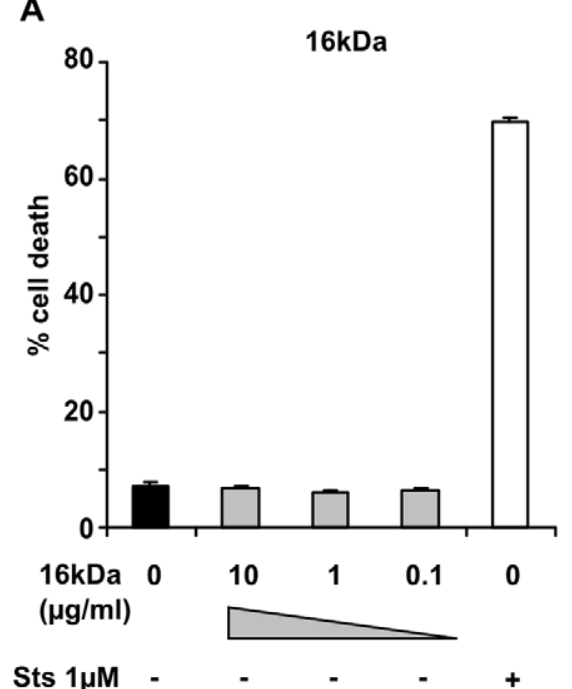

D

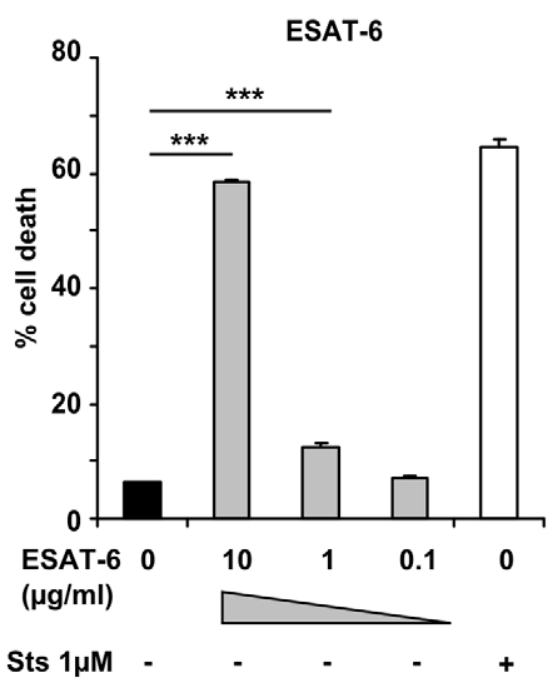

B

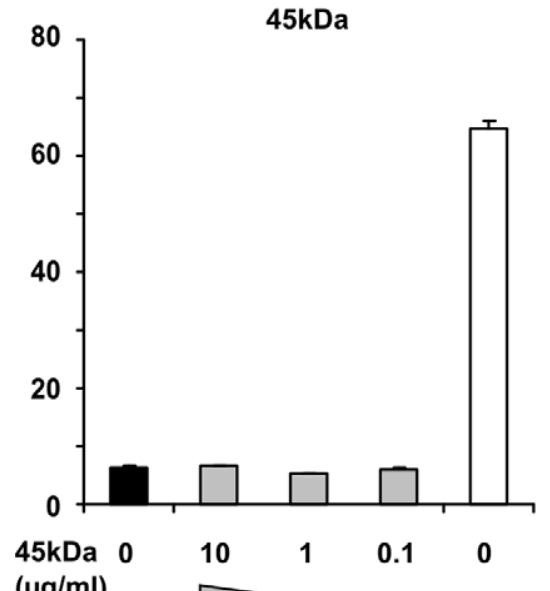

C

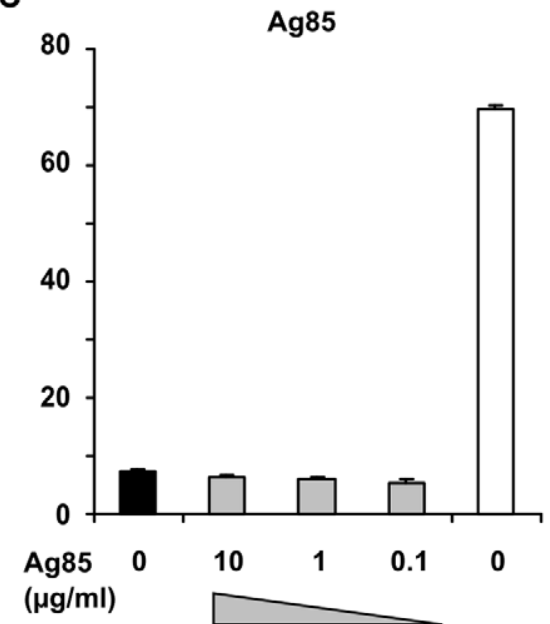

Sts $1 \mu \mathrm{M}-\quad$ - $\quad-\quad-\quad+$ Sts $1 \mu \mathrm{M}$

E

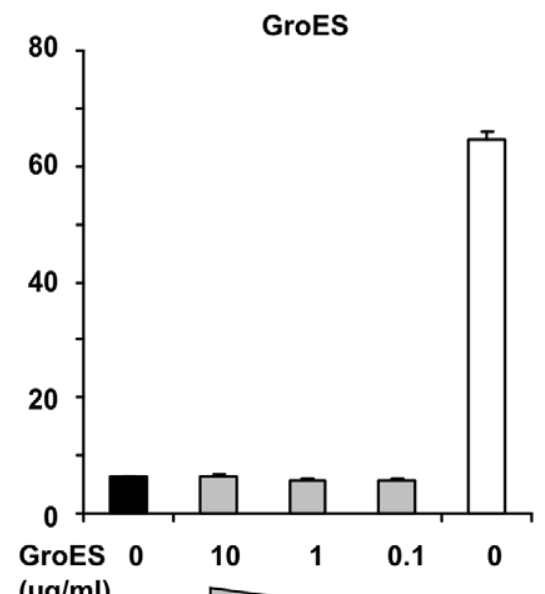

$(\mu \mathrm{g} / \mathrm{ml})$

Sts $1 \mu \mathrm{M}$ -

$\mathbf{F}$

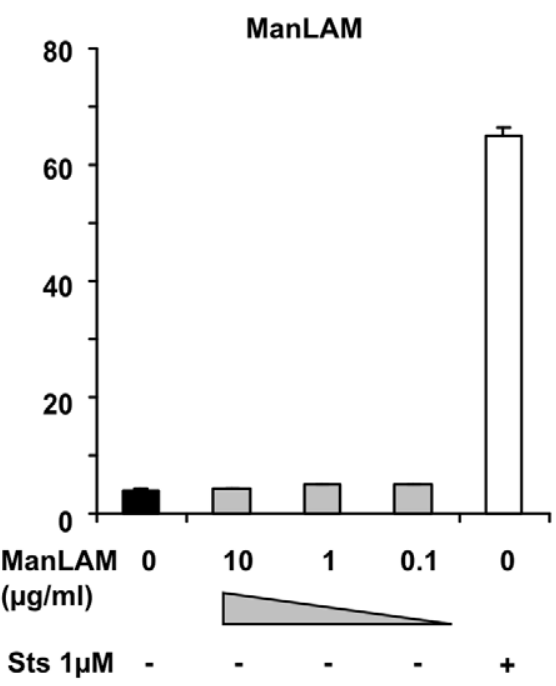

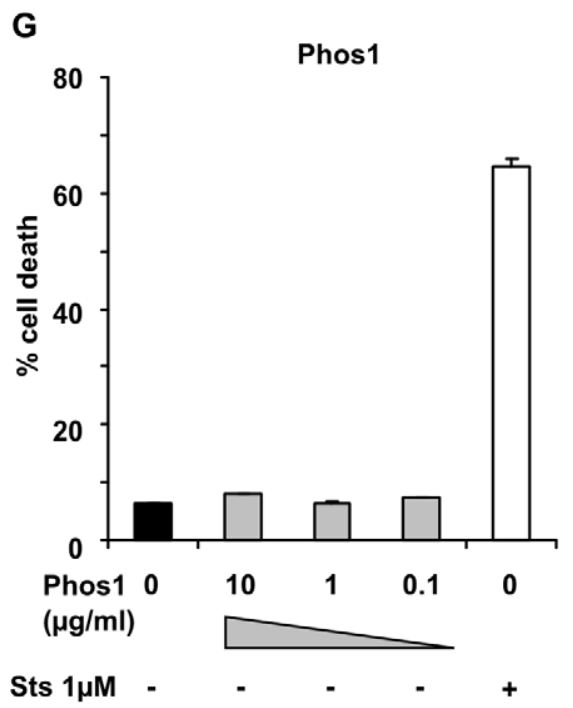
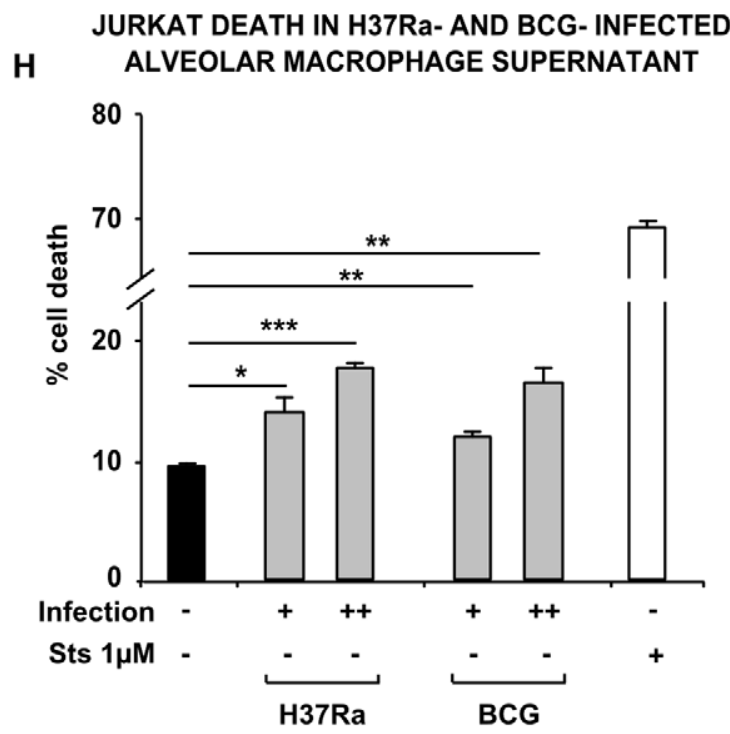
Figure 4. T cell death after exposure to M.tuberculosis secreted antigens. Jurkat T cells were exposed for $24 \mathrm{~h}$ to a panel of secreted factors derived from Mtb. No increase in cell death occurred when T cells were incubated with $16 \mathrm{kDa}$, $45 \mathrm{kDa}$, Antigen 85 complex, GroES, ManLAM or Phos1 (A-C, E-G, respectively, shaded bars), however elevated death occurred in cells incubated with ESAT-6 at $10 \mu \mathrm{g} / \mathrm{ml} \mathrm{or} 1 \mu \mathrm{g} / \mathrm{ml}$ (D). $1 \mu \mathrm{M}$ Staurosporine was used as a positive control in each case (open bars); vehicle control was either PBS or DMSO in the case of ManLAM (closed bars). Supernatants of AMs infected with H37Ra or M.bovis BCG both significantly increased T cell death ( $\mathrm{H}$, shaded bars), compared with uninfected AM supernatants $(H$, closed bars). Data in each panel are from one representative experiment, showing mean percentage cell death \pm SEM from incubations performed in triplicate. ${ }^{*}=p<0.05,{ }^{* *}=p<0.01,{ }^{* * *}=p<0.001$, Student's $t$ test relative to vehicle (A-G) or uninfected (H) control. doi:10.1371/journal.pone.0038488.g004

supernatants from uninfected AMs, $5.85 \pm 0.13 \%$ cell death was observed, whereas in supernatants from low and high MOI Mtbinfected AMs, this increased significantly $(\mathrm{p}<0.001)$ to $18.12 \pm 0.24 \%$ and $21.13 \pm 0.25 \%$, respectively. $1 \mu \mathrm{M}$ Staurosporine used as a positive cell-killing control caused $67.33 \pm 0.85 \%$ death (fig. 2A). In this, and subsequent experiments, an automated image analysis strategy (figure S1) was used to clearly identify apoptotic cells that had condensed/fragmented nuclei and/or PI staining, and discriminate them from live cells (fig. 2C).

In the past, we have found that PMA-treated THP-1 human macrophages serve as a good model for the human alveolar macrophage, with respect to innate responses after infection with Mtb. Specifically we have shown that the host responses of infection-induced macrophage apoptosis and phagolysosomal maturation arrest are well reproduced in this cell-line [23,24]. To test whether PMA-treated THP-1 cells could be used as a model human macrophage to study the mechanism of networked $\mathrm{T}$ cell death, we investigated the toxic effect of infected THP-1 macrophage supernatants on T cells. Peripheral blood T lymphocytes were incubated for $24 \mathrm{~h}$ in supernatants from Mtb-infected THP-1 macrophages, or supernatants from uninfected macrophages as controls. $15.33 \pm 0.60 \%$ cell death occurred in PBTLs exposed to uninfected supernatants, whilst in those incubated in low and high MOI supernatants, this increased significantly to $28.80 \pm 0.41 \%$ and $28.81 \pm 1.53 \%(\mathrm{p}<0.001$ and 0.01$)$, respectively (fig. 2A). In order to investigate whether PBTLs could be replaced with a cell line in further studies, we repeated this experiment using the Jurkat $\mathrm{T}$ cell line as a death signal target. In Jurkat cells cultured in supernatants from uninfected THP-1 macrophages, $9.57 \pm 0.03 \%$ cell death was observed following incubation, whereas in cells cultured in low MOI and high MOI-infected macrophage supernatants, significantly $(p<0.001)$ enhanced cell death was observed, with percentage dead cells increasing to $23.33 \pm 0.60 \%$ and $25.68 \pm 0.69 \%$ respectively (fig. 2A). Staurosporine was used routinely as a positive control, and significantly $(\mathrm{p}<0.001)$ increased cell death to $68.45 \pm 0.57 \%$ and $72.61 \pm 1.41 \%$ in PBTLs and Jurkats, respectively.

\section{T Cell Killing by Infected Macrophage Supernatants is Dose-dependent}

To confirm that soluble mediators contained in the medium of infected macrophages were responsible for $\mathrm{T}$ cell death, we carried out a dose-response assay using infected supernatants. In uninfected control THP-1 supernatants, $6.11 \pm 0.36 \%$ Jurkat T cell death was observed. This was significantly $(\mathrm{p}<0.001)$ elevated in undiluted, high MOI-infected THP-1 supernatant, to $17.23 \pm 0.49 \%$, and progressively reduced to $10.88 \pm 0.45 \%$ at a $50 \%$ dilution, and $9.49 \pm 0.42 \%$ at a $20 \%$ dilution, both of which were also significantly $(\mathrm{p}<0.01)$ higher than the uninfected control (fig. 2B).

\section{Macrophage-free M. tuberculosis Bacilli are not Sufficient to Signal T Cell Death}

Mtb bacilli alone, and without macrophages, were insufficient to cause toxicity to T cells; in PBTLs coincubated for $24 \mathrm{~h}$ with live bacilli at $1: 1,1: 5$ and $1: 10$ ratios; $12.89 \pm 0.94 \%, 11.72 \pm 1.55 \%$ and $12.01 \pm 0.34 \%$ cell death was observed, respectively, and none of these was significantly higher than the medium-only control, where $9.21 \pm 0.36 \%$ cell death occurred (fig. $3 \mathrm{~A}$ ). This result was also seen in Jurkats coincubated for $24 \mathrm{~h}$ with live bacilli at 1:1, 1:5 and $1: 10$ ratios; $6.50 \pm 0.28 \%, 4.62 \pm 0.34$ and $5.82 \pm 0.57 \%$ cell death was observed, and again this was not significantly higher than in cells incubated in the absence of Mtb, where $3.77 \pm 0.38 \%$ death was observed (fig. 3B). Culture medium from Mtb H37Ra growing in the log phase was also applied Jurkat T cells, in order to investigate whether factors released during normal growth of the bacilli in culture broth could perturb viability. No significant increase was observed in cells incubated in complete RPMI supplemented with 10,25 or $50 \%$ of Mtb-conditioned medium; $1.93 \pm 0.12 \%, 2.05 \pm 0.07 \%$ and $4.37 \pm 0.88 \%$ cell death was observed, respectively, whilst $2.86 \pm 0.22 \%$ was observed in the unsupplemented control. $1 \mu \mathrm{M}$ staurosporine induced significantly $(\mathrm{p}<0.001)$ enhanced cell death, at 58.53 $\pm 0.18 \%$ (fig. 3C).

\section{T Cell Death Mediated by Secreted Antigens of M. tuberculosis}

To examine whether $\mathrm{T}$ cell death in our system was attributable to other specific secreted proteins from $\mathrm{Mtb}$, and since such secreted factors have previously been shown to alter immune cell survival $[25,26,27]$ and activity [28], we exposed Jurkat cells to a panel of Mtb-derived factors. In Jurkat cells incubated in the presence of ESAT-6 at concentrations of $10 \mu \mathrm{g} / \mathrm{ml}, 1 \mu \mathrm{g} / \mathrm{ml}$ and $0.1 \mu \mathrm{g} / \mathrm{ml}, 58.33 \pm 0.58 \%, 12.43 \pm 0.55 \%$ and $7.04 \pm 0.23 \%$ cell death was observed. At $10 \mu \mathrm{g} / \mathrm{ml}$ and $1 \mu \mathrm{g} / \mathrm{ml}$, cell death was significantly $(\mathrm{P}<0.001)$ elevated above that of the vehicle control, where $6.35 \pm 0.16 \%$ death was observed. Staurosporine $1 \mu \mathrm{M}$ was used as a positive cell killing stimulus, and induced $64.63 \pm 1.34 \%$ death. Elevated death was not observed in T cells incubated with other secreted antigens such as $16 \mathrm{kDa}, 45 \mathrm{kDa}$, Antigen 85 complex, GroES, ManLAM or Phosl (fig. 4A-G). To examine whether ESAT- 6 could be the principal mediator of T cell death in our system, we performed AM infections using Mtb H37Ra in parallel with M.bovis BCG, then cultured Jurkat T cells in the resulting cell-free supernatants as described previously. In uninfected AM supernatants, T cell death was 9.56 $\pm 0.22 \%$; this significantly increased to $14.39 \pm 1.38 \% \quad(\mathrm{p}<0.05)$ and $18.30 \pm 0.31 \%(\mathrm{p}<0.001)$ in low and high MOI H37Ra-infected AM supernatants, respectively. In low and high MOI BCGinfected AM supernatants, T cell death also increased significantly $(\mathrm{p}<0.01)$ to $12.38 \pm 0.52 \%$ and $17.1 \pm 0.91 \%$, respectively (fig. $4 \mathrm{H}$ ). No significant difference was found when $\mathrm{T}$ cell death in H37Rainfected AM supernatants at low or high MOI was compared with that in BCG-infected AM supernatants at the same MOIs.

\section{Cell Death Induction by Infected Macrophage Supernatants is Caspase-dependent, but not Mediated by TNF- $\alpha$ or Fas}

To further delineate the factors responsible for $\mathrm{T}$ cell killing in macrophage conditioned medium, a number of blocking strategies were employed. Firstly, addition of the pan-caspase inhibitor, Z- 
A

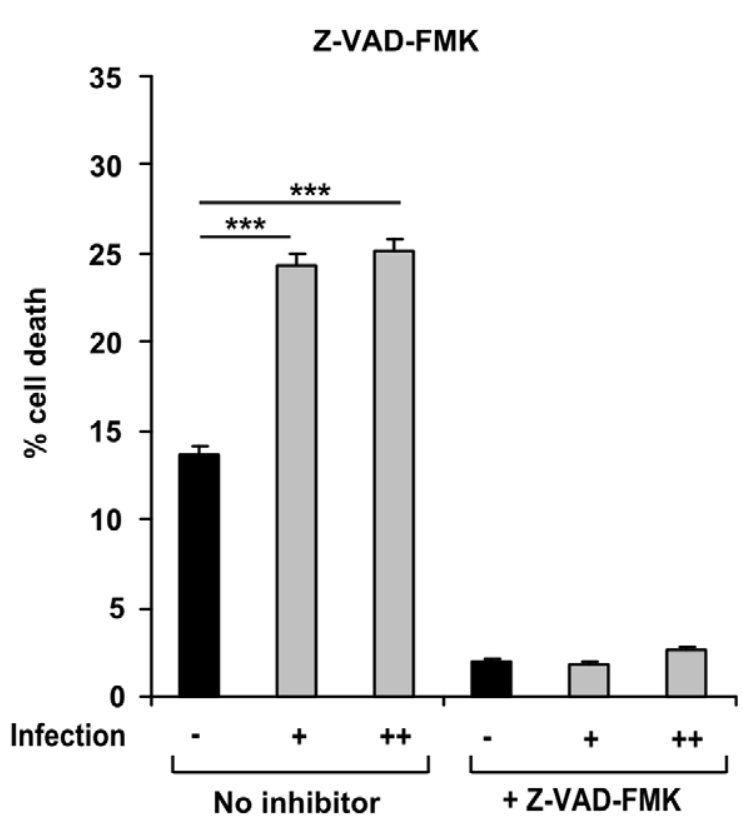

C

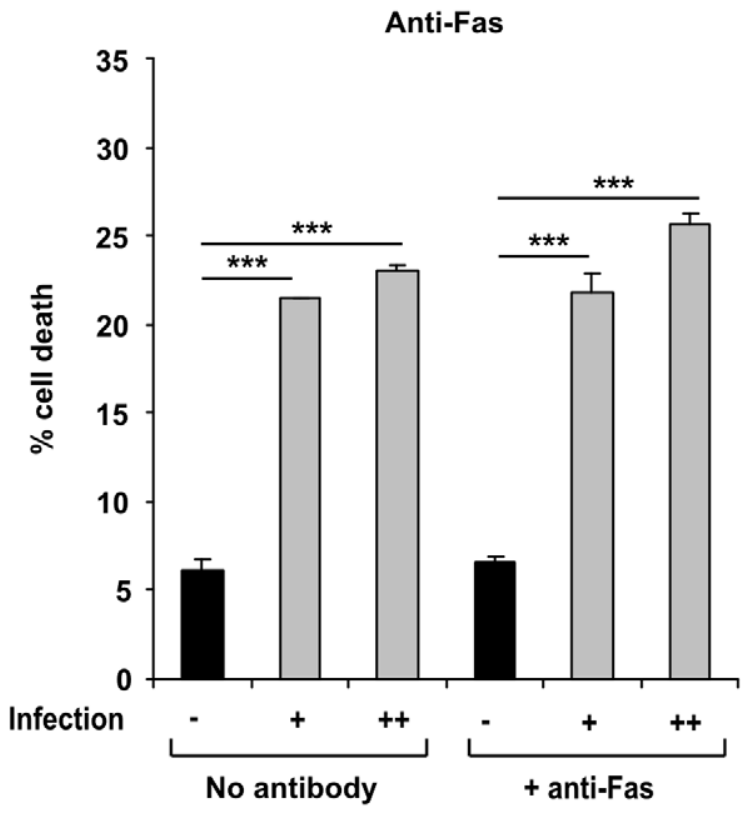

B

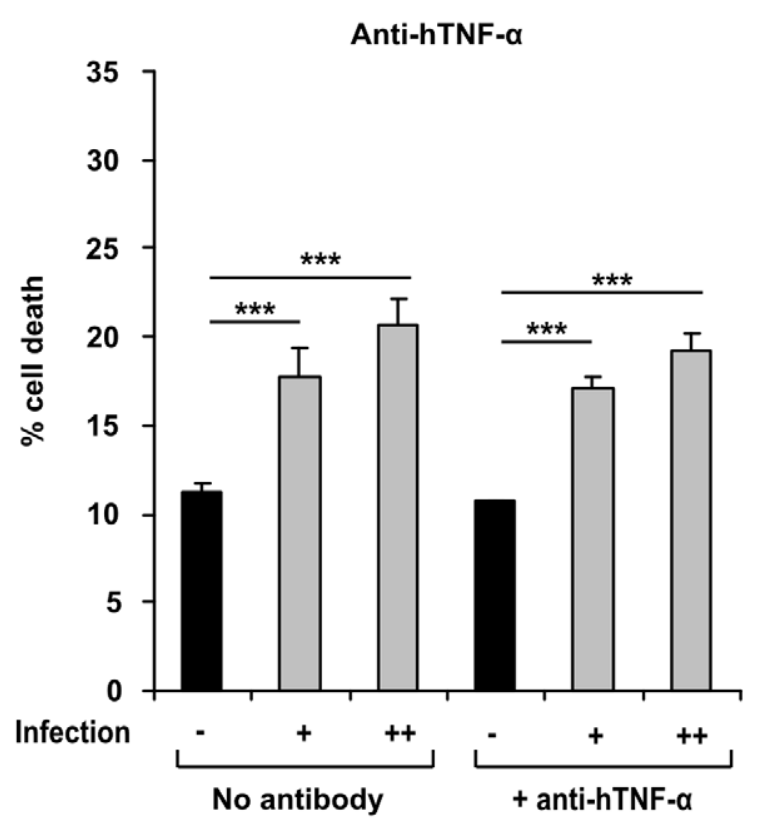

D

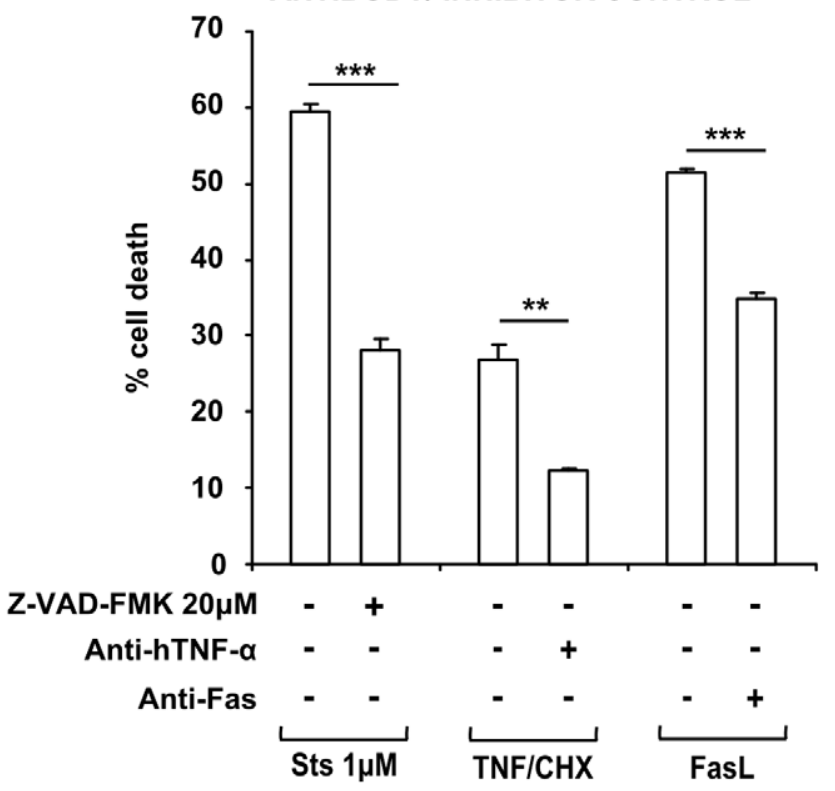

Figure 5. T cell death in M.tuberculosis-infected macrophage supernatants is caspase-dependent, and independent of TNF- $\alpha$ and Fas. (A) Addition of the pan-caspase inhibitor Z-VAD-FMK mitigated cell death induced by low MOI and high MOI-infected macrophage supernatants (shaded bars, infection + and ++ respectively), as well as background cell death observed in the uninfected control supernatants (closed bars, infection -). Cell death in infected supernatants was not mitigated by coincubation with blocking antibodies to TNF- $\alpha$ (B) or Fas (C), and in each case was significantly higher than in uninfected control supernatants (closed bars). Cell death induced by positive controls (D) (1 $\mu$ M Staurosporine, $5 \mathrm{ng} /$ $\mathrm{ml}$ recombinant human TNF- $\alpha+0.2 \mu \mathrm{g} / \mathrm{ml}$ cycloheximide and $10 \mathrm{ng} / \mathrm{ml}$ recombinant human Fas ligand) was in each case significantly reduced by coincubation with the corresponding inhibitor (open bars). Data shown in each panel are from one representative experiment, showing mean percentage cell death \pm SEM from triplicate incubations. ${ }^{* *}=p<0.01,{ }^{* * *}=p<0.001$, Student's $t$ test relative to uninfected control (A-C), or positive control relative to inhibitor (D).

doi:10.1371/journal.pone.0038488.g005

VAD-FMK to infected macrophage culture supernatants before incubation with $\mathrm{T}$ cells attenuated cell death, indicating that the effect was caspase-dependent. In cells incubated without inhibitor, cell death in medium from uninfected macrophages was $13.66 \pm 0.45 \%$, which increased significantly $(\mathrm{p}<0.001)$ to
$24.39 \pm 0.61 \%$ and $25.07 \pm 0.81 \%$ in low MOI and high MOI supernatants respectively. Following incubation in the same supernatants after addition of $20 \mu \mathrm{M}$ Z-VAD-FMK, cell death was $2.01 \pm 0.19 \%, 1.88 \pm 0.03 \%$ and $2.56 \pm 0.03 \%$ in uninfected, low MOI and high MOI supernatants, respectively (fig. 5A). In 
A

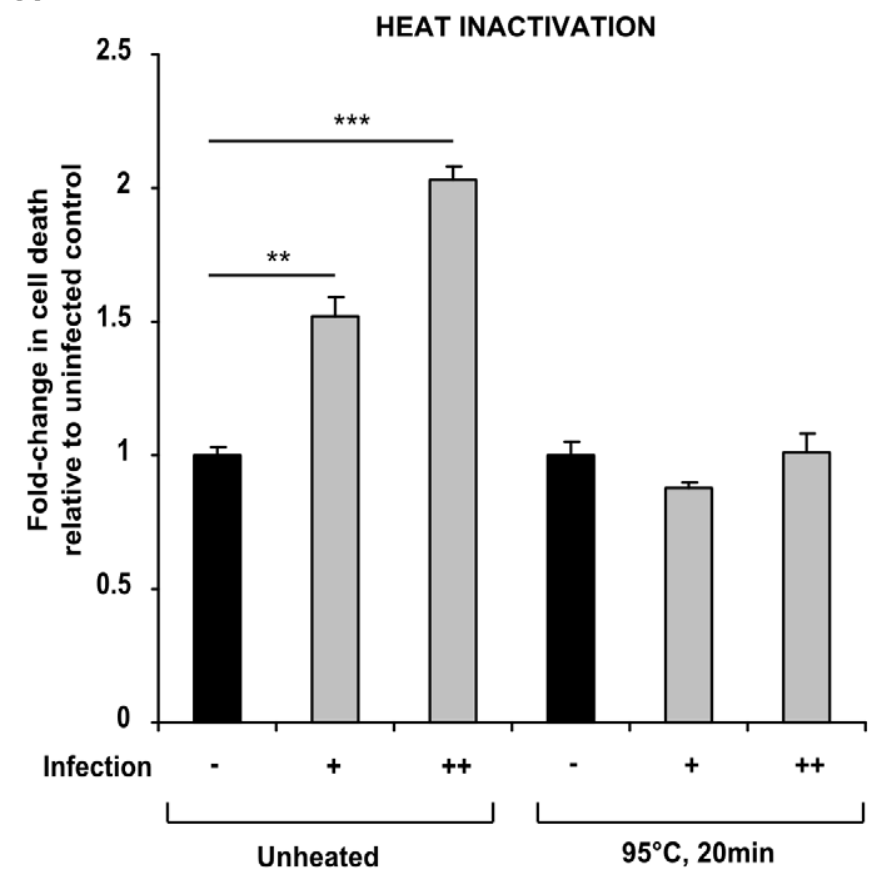

B

MOLECULAR WEIGHT SEPARATION $25 \%$ DILUTION
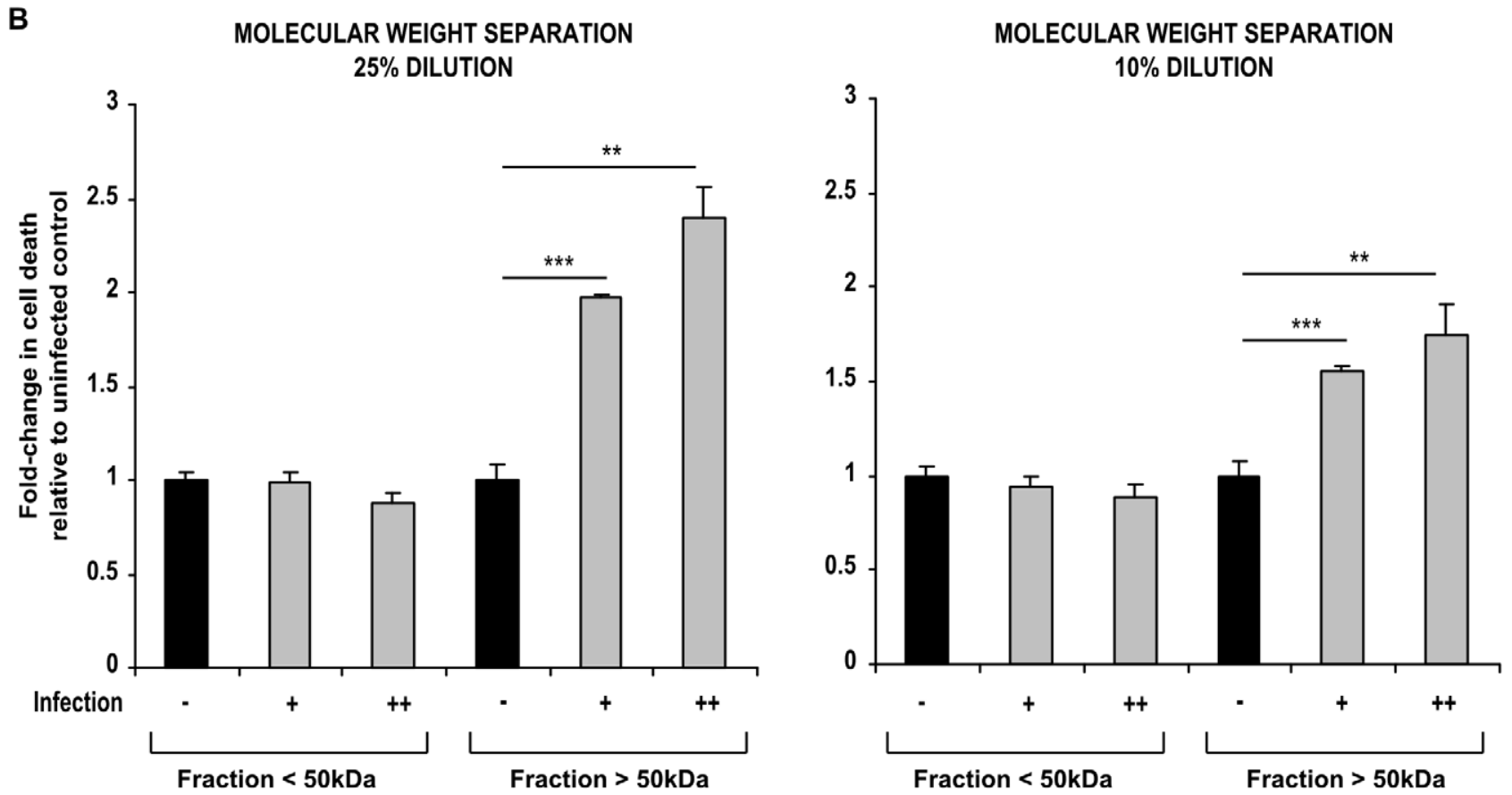

Figure 6. T cell death in M.tuberculosis-infected macrophage culture supernatants is mediated by heat-sensitive factor(s) greater than $50 \mathrm{kDa}$ in molecular size. (A) Heat inactivation $\left(95^{\circ} \mathrm{C}, 20 \mathrm{~min}\right.$ ) of supernatants from low $\mathrm{MOI}$ and high MOl-infected macrophages (shaded bars, infection + and ++ respectively) inhibited induction of Jurkat $T$ cell death. (B) Death-inducing factor(s) in infected macrophage supernatants were retained in the $>50 \mathrm{kDa}$ fractions following molecular size separation, and killed Jurkat T cells in a dose-dependent manner (25\% and $10 \%$ dilution). Data shown in each panel are from one representative experiment, showing fold-change in cell death \pm SEM in low MOI and high MOIinfected macrophage supernatants (shaded bars, infection + and ++ , respectively) relative to uninfected control (closed bars), from incubations performed in triplicate. Each experiment was repeated a minimum of three times. ${ }^{* *}=p<0.01,{ }^{* * *}=p<0.001$, Student's $t$ test relative to uninfected control.

doi:10.1371/journal.pone.0038488.g006

positive controls, $1 \mu \mathrm{M}$ staurosporine induced $59.45 \pm 0.97 \%$ cell death, which was significantly $(\mathrm{p}<0.001)$ mitigated by coincubation with $20 \mu \mathrm{M}$ Z-VAD-FMK, to $28.14 \pm 1.35 \%$ (fig. 5D).
Secondly, supernatants from infected macrophages were applied to $\mathrm{T}$ cells in the presence of TNF- $\alpha$ blocking antibody, at a concentration of $5 \mu \mathrm{g} / \mathrm{ml}$, or isotype $\operatorname{IgG}$ at the same 
concentration. In the presence of isotype control antibody, $11.29 \pm 0.10 \%$ death occurred in cells incubated in uninfected macrophage supernatants. This increased significantly $(\mathrm{p}<0.001)$ to $17.79 \pm 0.38 \%$ and $20.63 \pm 0.45 \%$ in cells incubated in low and high MOI-infected macrophage supernatants. This cytotoxicity was not inhibited by coincubation with anti-hTNF- $\alpha$; cell death increased significantly from $10.72 \pm 0.63 \%$ in the uninfected supernatants up to $17.13 \pm 0.13 \%$ and $19.18 \pm 0.51 \%(\mathrm{p}<0.001$ in both cases) in low and high MOI-infected macrophage supernatants, respectively (fig. $5 \mathrm{~B}$ ). In positive controls, $5 \mathrm{ng} / \mathrm{ml}$ recombinant human TNF- $\alpha+0.2 \mu \mathrm{g} / \mathrm{ml}$ cycloheximide caused $26.96 \pm 1.82 \%$ cell death in Jurkats incubated in the presence of isotype control $\mathrm{IgG}$, which was significantly $(\mathrm{p}<0.01)$ reduced to $12.22 \pm 0.23 \%$ in the presence of anti-hTNF- $\alpha$ (fig. 5D).

Anti-Fas blocking antibody, or isotype control IgG were added at a concentration of $2.5 \mu \mathrm{g} / \mathrm{ml}$ to supernatants. Cell death increased significantly from $6.16 \pm 0.65 \%$ in uninfected macrophage supernatants up to $21.44 \pm 0.12 \%(\mathrm{p}<0.001)$ in low MOI, and $23.03 \pm 0.38 \%(p<0.001)$ in high MOI-infected macrophage supernatants in the presence of isotype control $\mathrm{IgG}$, and this pattern was recapitulated in supernatants in the presence of antiFas, where cell death increased from $6.55 \pm 0.42$ in uninfected supernatants to $21.79 \pm 1.13 \%$ and $25.70 \pm 0.58 \%$ in low and high MOI-infected supernatants, respectively $(p<0.001$ in both cases) (fig. 5C). In positive controls, recombinant human Fas ligand induced $51.48 \pm 0.43 \%$ cell death, which was significantly reduced to $34.84 \pm 0.88 \%(\mathrm{p}<0.001)$ (fig. $5 \mathrm{D})$.

\section{The Cell Death Signal of Infected Macrophage Supernatants is Heat-labile and Mediated by Factor(s) Greater than 50 KiloDaltons in Molecular Size}

To investigate the composition of the signalling factor(s) that induced $\mathrm{T}$ cell death, supernatants from uninfected and infected macrophages were heat-denatured at $95^{\circ} \mathrm{C}$ for $20 \mathrm{~min}$, and then applied to Jurkat T cells. Following $24 \mathrm{~h}$ incubation, cell death was measured by Hoechst/PI staining, and expressed as fold-change in death relative to uninfected control. Unheated supernatants from low and high MOI-infected macrophages caused a significant $(\mathrm{p}<0.01, \mathrm{p}<0.001$ respectively) fold-increase in cell death to $1.52 \pm 0.07$ and $2.04 \pm 0.05$ of that in the uninfected control supernatants. This effect was mitigated by heat denaturing; in Jurkats incubated in heat-treated supernatants, fold-change in cell death was $0.88 \pm 0.02$ and $1.01 \pm 0.08$ of that in uninfected control supernatants (fig. 6A).

Subsequently, culture supernatants were passed through $50 \mathrm{kDa}$ molecular weight cutoff filters, diluted in fresh medium as outlined in methods, and then used to culture Jurkat T cells. Cell death was measured by PI/Hoechst staining and expressed as fold-change relative to the uninfected supernatants. Following $24 \mathrm{~h}$ incubation, death was not increased by the filtrate containing molecules below $50 \mathrm{kDa}$ in size, where low and high MOI supernatant $<50 \mathrm{kDa}$ fractions at $25 \%$ dilution did not induce any significant foldchange in death compared to that of the control uninfected supernatant $(0.99 \pm 0.05$ and $0.87 \pm 0.06$ fold-change relative to control, respectively). Conversely, a significant $(\mathrm{p}<0.001$ low MOI, $\mathrm{p}<0.01$ high MOI) increase was observed in death in cells incubated in the low and high MOI $>50 \mathrm{kDa}$ fractions at $25 \%$ dilution, causing a change of $1.97 \pm 0.02$-fold, and $2.40 \pm 0.17$-fold respectively, relative to control (fig. 6B). These results were recapitulated at $10 \%$ dilution of the supernatant filtrates and retentates; again no significant increase in cell death was observed in $\mathrm{T}$ cells cultured in the $<50 \mathrm{kDa}$ fractions of low and high MOI supernatants $(0.99 \pm 0.05$ and $0.87 \pm 0.06$ fold-change relative to uninfected control), whilst cell death induction was maintained in the $>50 \mathrm{kDa}$ fractions; low MOI supernatant retentate caused a $1.56 \pm 0.04$-fold increase in cell death, whilst high MOI supernatant retentate caused a $1.75 \pm 0.08$-fold increase, both of which were significantly $(p<0.001$ and $p<0.01$ respectively) higher than control (fig. 6B).

\section{Discussion}

In our tuberculosis patients, we found that lymphopenia was prevalent and reversible after treatment for this infectious disease. This systemic lack of $\mathrm{T}$ cell function may be linked to the poor performance of clinical tests for Mtb infection in tuberculosis patients that rely on lymphocyte function - such as the Tuberculin skin test and the Interferon- $\gamma$ release assay. To study the effect of Mtb-infected macrophages on lymphocyte depletion, we examined T cell viability when exposed to the cell-free culture supernatant of infected phagocytes. Our results show that culture supernatants from Mtb-infected human macrophages induce contact-independent $\mathrm{T}$ cell apoptosis, in a dose-dependent manner. We found that $\mathrm{T}$ cell survival was unaffected by (macrophage-free) Mtb bacilli or their secreted products in bacterial culture, with the exception of ESAT-6, which reliably induced $\mathrm{T}$ cell death. However, subsequent experiments showed networked $\mathrm{T}$ cell death occurred in our system even when culture supernatants of AMs infected with the ESAT-6-deficient M.bovis BCG were used. Although T cell death in macrophage supernatants was caspase-dependent, it was not mediated by TNF- $\alpha$ or Fas. Further characterisation of the deathinducing factor(s) revealed them to be heat-labile and greater than $50 \mathrm{kDa}$ in molecular size.

During infection by M.tuberculosis, several strategies facilitate pathogenesis and avoidance of bacillary destruction, including perturbation of phagosomal maturation [23], manipulation of phagocyte viability in order to preserve the replicative environment and subsequently facilitate release of newly-produced bacilli [29] and downmodulation of responsiveness to activating signals [30]. Alteration of host cell signalling responses can also elicit favourable conditions for Mtb [31], and secreted virulence factors have also been shown to play a role in modulating immune cell signalling [32]. Inducing death of host $\mathrm{T}$ cells, thereby disrupting their interaction with infected phagocytes, may be a further mechanism by which Mtb evades host immunity.

Elimination of immune effector cells in the proximity of infected phagocytes is thematically consistent with the concept of establishing the Mtb infection site as an immune-privileged location [33,34], and it is clear that multiple mechanisms contribute to this process. Contact-dependent death of nearby, non-infected cells has been shown in previous studies $[14,16,18]$, but in our system an additional mode of $\mathrm{T}$ cell killing was found, which was mediated by soluble factors. Other distinct networked cell signalling effects following Mtb infection are also known to occur - for example, Green et al. demonstrated that conditioned medium from infected monocytes elicited release of matrix metalloproteinase from microglia, representing a novel mechanism of pathology arising from TB disease in the central nervous system [35].

Since $\mathrm{T}$ cells arriving at the site of infection are likely to be activated, further investigation is now warranted into the importance of activation status on Mtb infection- induced cell death. However, whilst Sharma et al. have shown that activated T cells undergo increased apoptosis when exposed to Mtb-infected macrophages [16], our own experiments exposing unstimulated primary $\mathrm{T}$ cells to supernatants from infected macrophages have also shown increased cell death. It is therefore still unclear to what degree activation status influences infection-induced networked 
cell death, and further examination of the susceptibility of particular subsets of $\mathrm{T}$ cells, such as CD4+ or CD8+, would also be of utility.

Exposure to viable Mtb bacilli did not cause an increase in $\mathrm{T}$ cell death during our coculture experiments, nor did incubation in their spent culture medium. However, changing physiological conditions, such as those encountered by Mtb upon phagocytosis for example, may lead to the expression of a distinct subset of genes that mediate bacillary survival and persistence [36,37]. Our model has excluded a role for Mtb bacilli in isolation causing $\mathrm{T}$ cell killing, but virulence factors that are upregulated following intracellular infection of phagocytes might still contribute to networked $\mathrm{T}$ cell death. We saw that ESAT-6 was sufficient to cause increased $\mathrm{T}$ cell death. However, as mentioned above, it is unlikely to be the major contributor to death in our system, since experiments demonstrated the apoptosis-inducing effects of supernatants from BCG-infected macrophages. BCG does not express ESAT-6 due to deletion of the RDl locus [38]. In addition, our molecular weight separation experiments show that the proapoptotic signals are mediated by infected macrophage supernatant factors greater than $50 \mathrm{kDa}$ in size. Although ESAT-6 may be present in $>50 \mathrm{kDa}$ complexes with other Mtb virulence factors $[39,40]$, it is still unlikely to be the death factor in our presented experiments using Mtb H37Ra. This is because H37Ra does not secrete abundant ESAT-6 due to a S219L point mutation in the predicted DNA binding region of the regulator PhoP [41].

TNF- $\alpha$ and Fas/Fas Ligand interactions have both been shown to regulate cell death during mycobacterial infections [17]. Key studies by Sharma et al., and Hirsch et al., had previously implicated TNF- $\alpha$ and Fas in deletion of $\mathrm{T}$ cells during Mtb infection in a contact-dependent manner [16] and in a mixed PBMC-Mtb coincubation system [15], respectively. The latter implicated TNF- $\alpha$, TGF- $\beta$, Fas and modulation of Bcl-2 expression in mediating changes in $\mathrm{T}$ cell viability in $\mathrm{Mtb}$ infection, but also showed that the mechanisms varied between patients. When specifically interrogating the effects of soluble mediators in our own supernatant transfer model, we found that the addition of blocking antibodies against either TNF- $\alpha$ or Fas to the infected macrophage supernatants did not reduce killing of $\mathrm{T}$ cells. It is therefore clear that an additional TNF- $\alpha$ - and Fasindependent mode of action may exist, that is contact-independent, and can cause $\mathrm{T}$ cells to undergo apoptosis, mediated exclusively by soluble factors released from infected phagocytes.

Heat treatment showed that the signal(s) present in infected macrophage supernatants responsible for $\mathrm{T}$ cell killing were heatlabile, and we subsequently employed a molecular size separation protocol in order to more clearly delineate these factor(s). In these experiments, the cytotoxic effect separated to the $>50 \mathrm{kDa}$ fraction, and suggested that a large protein or multimeric cytokines could be responsible. The lack of increased death in cells incubated in the $<50 \mathrm{kDa}$ fraction indicated that small molecule mediators such as nitric oxide [42] or ATP [43], though both relevant in control of tuberculosis infection in macrophages $[7,44]$, are not responsible for the $\mathrm{T}$ cell death observed in our experimental system. Furthermore, $\mathrm{T}$ cell killing activity of infected supernatants was retained even when the $>50 \mathrm{kDa}$ fractions were diluted to $10 \%$ in fresh medium, precluding the possibility that simple nutrient depletion within the supernatants was responsible for the cytotoxic effect.

Networked $\mathrm{T}$ cell death by soluble host- and/or pathogenderived mediators released during Mtb infection may contribute to the $\mathrm{T}$ cell lymphopenia observed in patients with active TB disease; furthermore, premature deletion of $\mathrm{T}$ cells as they approach the infection site could inhibit the delivery of activating cytokines such as IFN- $\gamma$, thus rendering the infected phagocytes incompetent to degrade and clear the pathogen. A similar mode of infection-induced networked death signalling occurs during infection by other intracellular bacteria such as Chlamydia trachomatis [45]. In the case of M.tuberculosis, this phenotype likely represents one of several manipulations of host immunity that enable persistence. It is possible that by protecting $\mathrm{T}$ cells from this toxic influence of infected macrophages in-vivo, the balance may be tipped towards preserving immune effector capacity, and improved disease resolution.

\section{Supporting Information}

Figure S1 Automated cell death image analysis. Images were acquired at $10 \times$ magnification using 360/460 $\mathrm{nm}$ and 535/ $620 \mathrm{~nm}$ excitation/emission filter sets to detect fluorescence from Hoechst and PI staining, respectively (A; bar $50 \mu \mathrm{m}$, Hoechst/PI intensity shown for the same field of view for Jurkat $\mathrm{T}$ cells incubated in control uninfected macrophage supernatant). Normal nuclei were distinguishable from condensed nuclei (example arrow 1), whilst mitotic cells did not show increased Hoechst staining, thus precluding false-positives (arrow 2). PI staining was also clearly distinguishable (arrow 3). Intensity measurements for Hoechst and PI in each cell were analysed on a cell-by-cell basis; cells with condensed nuclei were identified by an elevated coefficient of variance of nuclear intensity (nuclear intensity $\mathrm{CV}$; a measure of the degree of variation above the nuclear intensities of other cells in that field) above a user-defined threshold, and PIpositivity was also identified by intensity above a user-defined threshold. Using a decision-tree protocol, cells were categorised into four classes: Live, PI-positive, condensed nucleus, and condensed nucleus + PI. The latter three categories were then summed to give percentage cell death for each field of view (B). 12 fields of view were acquired per treatment, and each treatment was performed in triplicate.

(TIF)

\section{Acknowledgments}

We gratefully acknowledge the contribution of the Dublin Centre for Clinical Research, St. James's Hospital, and their research nurses, for their assistance in the procurement of BAL. We thank Dr. Mary O'Sullivan and Dr. Seonadh O'Leary for kind assistance and advice.

\section{Author Contributions}

Conceived and designed the experiments: SHFM EW ERD JK. Performed the experiments: SHFM EW MMC ERD. Analyzed the data: SHFM EW MMC JK. Contributed reagents/materials/analysis tools: AMM JK. Wrote the paper: SHFM JK. Performed and analysed patient lymphocyte counts: PN WMC. Recruited patients and performed bronchoalveolar lavage for alveolar macrophage isolation: AMM JK.

\section{References}

1. Davoudi S, Rasoolinegad M, Younesian M, Hajiabdolbaghi M, Soudbakhsh A, et al. (2008) CD4+ cell counts in patients with different clinical manifestations of tuberculosis. Brazilian Journal of Infectious Diseases 12: 483-486.

2. Jones BE, Oo MM, Taikwel EK, Qian D, Kumar A, et al. (1997) CD4 Cell Counts in Human Immunodeficiency Virus-Negative Patients with Tuberculosis. Clinical Infectious Diseases 24: 988-991.

3. Baena A, Porcelli SA (2009) Evasion and subversion of antigen presentation by Mycobacterium tuberculosis. Tissue Antigens 74: 189-204.

4. Schmolke M, García-Sastre A (2010) Evasion of innate and adaptive immune responses by influenza A virus. Cellular Microbiology 12: 873-880. 
5. Gutierrez MG, Master SS, Singh SB, Taylor GA, Colombo MI, et al. (2004) Autophagy Is a Defense Mechanism Inhibiting BCG and Mycobacterium tuberculosis Survival in Infected Macrophages. Cell 119: 753-766.

6. Blanchette J, Jaramillo M, Olivier M (2003) Signalling events involved in interferon- $\gamma$-inducible macrophage nitric oxide generation. Immunology 108 : 513-522.

7. Herbst S, Schaible UE, Schneider BE (2011) Interferon Gamma Activated Macrophages Kill Mycobacteria by Nitric Oxide Induced Apoptosis. PLoS ONE 6: e19105.

8. Pilheu JA, Salvo MCD, Gonzalez J, Rey D, Elias MC, et al. (1997) CD4+ Tlymphocytopenia in severe pulmonary tuberculosis without evidence of human immunodeficiency virus infection. The International Journal of Tuberculosis and Lung Disease 1: 422-426.

9. Hirsch CS, Toossi Z, Othieno C, Johnson JL, Schwander SK, et al. (1999) Depressed T-Cell Interferon- $\gamma$ Responses in Pulmonary Tuberculosis: Analysis of Underlying Mechanisms and Modulation with Therapy. Journal of Infectious Diseases 180: 2069-2073.

10. Egen JG, Rothfuchs AG, Feng CG, Winter N, Sher A, et al. (2008) Macrophage and $\mathrm{T}$ Cell Dynamics during the Development and Disintegration of Mycobacterial Granulomas. Immunity 28: 271-284.

11. Saunders BM, Britton WJ (2007) Life and death in the granuloma: immunopathology of tuberculosis. Immunol Cell Biol 85: 103-111.

12. Keane J, Remold HG, Kornfeld H (2000) Virulent Mycobacterium tuberculosis Strains Evade Apoptosis of Infected Alveolar Macrophages. The Journal of Immunology 164: 2016-2020.

13. Mustafa T, Wiker H, Mørkve O, Sviland L (2008) Differential expression of mycobacterial antigen MPT64, apoptosis and inflammatory markers in multinucleated giant cells and epithelioid cells in granulomas caused by Mycobacterium tuberculosis. Virchows Archiv 452: 449-456.

14. Mustafa T, Mogga SJ, Mfinanga SGM, Mørkve O, Sviland L (2006) Immunohistochemical analysis of cytokines and apoptosis in tuberculous lymphadenitis. Immunology 117: 454-462.

15. Hirsch CS, Johnson JL, Okwera A, Kanost RA, Wu M, et al. (2005) Mechanisms of Apoptosis of T-Cells in Human Tuberculosis. Journal of Clinical Immunology 25: 353-364.

16. Sharma S, Sharma M, Bose M (2008) Mycobacterium tuberculosis infection of human monocyte-derived macrophages leads to apoptosis of T cells. Immunol Cell Biol 87: 226-234.

17. Zhong J, Gilbertson B, Cheers C (2003) Apoptosis of CD4+ and CD8+ T cells during experimental infection with Mycobacterium avium is controlled by Fas/FasL and Bcl-2-sensitive pathways, respectively. Immunol Cell Biol 81: 480-486.

18. Kelly DM, ten Bokum AMC, O'Leary SM, O'Sullivan MP, Keane J (2008) Bystander Macrophage Apoptosis after Mycobacterium tuberculosis H37Ra Infection. Infect Immun 76: 351-360.

19. Schaible UE, Winau F, Sieling PA, Fischer K, Collins HL, et al. (2003) Apoptosis facilitates antigen presentation to T lymphocytes through MHC-I and CD1 in tuberculosis. Nat Med 9: 1039-1046.

20. Keane J, Balcewicz-Sablinska MK, Remold HG, Chupp GL, Meek BB, et al. (1997) Infection by Mycobacterium tuberculosis promotes human alveolar macrophage apoptosis. Infect Immun 65: 298-304

21. Ryan RC, O'Sullivan MP, Keane J (2011) Mycobacterium tuberculosis infection induces non-apoptotic cell death of human dendritic cells. BMC Microbiol 11: 237.

22. Gilbertson B, Zhong J, Cheers C (1999) Anergy, IFN- $\gamma$ Production, and Apoptosis in Terminal Infection of Mice with Mycobacterium avium. The Journal of Immunology 163: 2073-2080.

23. O'Leary S, O'Sullivan MP, Keane J (2010) IL-10 Blocks Phagosome Maturation in Mycobacterium tuberculosis-infected Human Macrophages. Am J Respir Cell Mol Biol. pp 2010-0319OC.

24. O'Sullivan MP, O'Leary S, Kelly DM, Keane J (2007) A Caspase-Independent Pathway Mediates Macrophage Cell Death in Response to Mycobacterium tuberculosis Infection. Infect Immun 75: 1984-1993.

25. Derrick SC, Morris SL (2007) The ESAT6 protein of Mycobacterium tuberculosis induces apoptosis of macrophages by activating caspase expression. Cellular Microbiology 9: 1547-1555.
26. Sanchez A, Espinosa P, Esparza MA, Colon M, Bernal G, et al. (2009) Mycobacterium tuberculosis 38-kDa Lipoprotein is Apoptogenic for Human Monocyte-derived Macrophages. Scandinavian Journal of Immunology 69: 20-28.

27. Wojtas B, Fijalkowska B, Wlodarczyk A, Schollenberger A, Niemialtowski M, et al. (2011) Mannosylated lipoarabinomannan balances apoptosis and inflammatory state in mycobacteria-infected and uninfected bystander macrophages. Microbial Pathogenesis 51: 9-21.

28. Mahon RN, Rojas RE, Fulton SA, Franko JL, Harding CV, et al. (2009) Mycobacterium tuberculosis Cell Wall Glycolipids Directly Inhibit CD4+ T-Cell Activation by Interfering with Proximal T-Cell-Receptor Signaling. Infect Immun 77: 4574-4583.

29. Danelishvili L, Yamazaki Y, Selker J, Bermudez LE (2010) Secreted Mycobacterium tuberculosis Rv3654c and Rv3655c Proteins Participate in the Suppression of Macrophage Apoptosis. PLoS ONE 5: e10474.

30. Singhal A, Jaiswal A, Arora VK, Prasad HK (2007) Modulation of Gamma Interferon Receptor 1 by Mycobacterium tuberculosis: a Potential Immune Response Evasive Mechanism. Infect Immun 75: 2500-2510.

31. Master SS, Rampini SK, Davis AS, Keller C, Ehlers S, et al. (2008) Mycobacterium tuberculosis Prevents Inflammasome Activation. Cell Host \& Microbe 3: 224-232.

32. Samten B, Wang X, Barnes PF (2009) Mycobacterium tuberculosis ESX-1 systemsecreted protein ESAT-6 but not CFP10 inhibits human T-cell immune responses. Tuberculosis 89: S74-S76.

33. Welsh KJ, Risin SA, Actor JK, Hunter RL (2010) Immunopathology of Postprimary Tuberculosis: Increased T-Regulatory Cells and DEC-205-Positive Foamy Macrophages in Cavitary Lesions. Clinical and Developmental Immunology 2011.

34. Mellor AL, Munn DH (2008) Creating immune privilege: active local suppression that benefits friends, but protects foes. Nat Rev Immunol 8: 74-80.

35. Green JA, Elkington PT, Pennington CJ, Roncaroli F, Dholakia S, et al. (2010) Mycobacterium tuberculosis Upregulates Microglial Matrix Metalloproteinase-1 and -3 Expression and Secretion via NF-kappaB and Activator Protein-1-Dependent Monocyte Networks. The Journal of Immunology 184: 6492-6503.

36. Gupta RK, Srivastava BS, Srivastava R (2010) Comparative expression analysis of rpf-like genes of Mycobacterium tuberculosis $\mathrm{H} 37 \mathrm{Rv}$ under different physiological stress and growth conditions. Microbiology 156: 2714-2722.

37. Mariani F, Cappelli G, Riccardi G, Colizzi V (2000) Mycobacterium tuberculosis $\mathrm{H} 37 \mathrm{Rv}_{\mathrm{v}}$ comparative gene-expression analysis in synthetic medium and human macrophage. Gene 253: 281-291.

38. Mahairas GG, Sabo PJ, Hickey MJ, Singh DC, Stover CK (1996) Molecular analysis of genetic differences between Mycobacterium bovis BCG and virulent M. bovis. J Bacteriol 178: 1274-1282.

39. Renshaw PS, Lightbody KL, Veverka V, Muskett FW, Kelly G, et al. (2005) Structure and function of the complex formed by the tuberculosis virulence factors CFP-10 and ESAT-6. Embo J 24: 2491-2498.

40. Wong KW, Jacobs WR, Jr. (2011) Critical role for NLRP3 in necrotic death triggered by Mycobacterium tuberculosis. Cell Microbiol 13: 1371-1384.

41. Frigui W, Bottai D, Majlessi L, Monot M, Josselin E, et al. (2008) Control of M.tuberculosis ESAT-6 Secretion and Specific T Cell Recognition by PhoP. PLoS Pathog 4: e33.

42. Tripathi P, Tripathi P, Kashyap L, Singh V (2007) The role of nitric oxide in inflammatory reactions. FEMS Immunology \& Medical Microbiology 51: 443-452.

43. Tsukimoto M, Maehata M, Harada H, Ikari A, Takagi K, et al. (2006) P2X7 Receptor-Dependent Cell Death Is Modulated during Murine T Cell Maturation and Mediated by Dual Signaling Pathways. The Journal of Immunology 177: 2842-2850.

44. Placido R, Auricchio G, Falzoni S, Battistini L, Colizzi V, et al. (2006) P2X7 purinergic receptors and extracellular ATP mediate apoptosis of human monocytes/macrophages infected with Mycobacterium tuberculosis reducing the intracellular bacterial viability. Cellular Immunology 244: 10-18.

45. Jendro M, Fingerle F, Deutsch T, Liese A, Köhler L, et al. (2004) Chlamydia trachomatis-infected macrophages induce apoptosis of activated $\mathrm{T}$ cells by secretion of tumor necrosis factor- $\alpha$ in vitro. Medical Microbiology and Immunology 193: 45-52. 